\title{
Binge eating in adults: prevalence and association with obesity, poor self-rated health status and body dissatisfaction
}

\author{
Giovanny Vinícius Araújo de França ${ }^{1, *}$, Denise Petrucci Gigante ${ }^{1}$ and \\ Maria Teresa Anselmo Olinto ${ }^{2,3}$ \\ 'Postgraduate Program in Epidemiology, Federal University of Pelotas, Rua Marechal Deodoro, $1160-3^{\circ}$ Piso, \\ Bairro Centro - Pelotas, RS, Cep: 96020-220 - Caixa Postal 464, Brazil: ${ }^{2}$ Postgraduate Program in Public \\ Health, University of Vale do Rio dos Sinos, São Leopoldo, Rio Grande do Sul, Brazil: ${ }^{3}$ Department of Nutrition, \\ Federal University of Health Science of Porto Alegre, Porto Alegre, Rio Grande do Sul, Brazil
}

Submitted 14 June 2012: Final revision received 1 February 2013: Accepted 5 February 2013: First published online 11 March 2013

\begin{abstract}
Objective: To estimate the prevalence of episodes of binge eating and to assess potential associations with nutritional status, satisfaction with current body weight, self-rated health status and self-rated body weight.

Design: A cross-sectional population-based study. Binge eating was assessed using adapted questions from the Brazilian Portuguese version of the Questionnaire on Eating and Weight Patterns and was defined as binging one or more times over the last 3 months before the interview.

Setting: City of Pelotas, southern Brazil.

Subjects: Individuals ( $n$ 2097) aged 20-59 years.

Results: The prevalence of binge eating and recurrent binge eating was $7 \cdot 9 \%$ and $2 \cdot 7 \%$, respectively. In the adjusted analysis, obesity, fair/poor self-rated health status and body dissatisfaction remained strongly associated with binge eating. Conclusions: The study showed a high prevalence of binge eating among adults in Pelotas, being higher among younger women, the obese and those who desired to weigh less. The current results are informative, but longitudinal studies would be needed to demonstrate the causal relationship between these events.
\end{abstract}

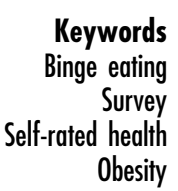

Binge eating was first described in 1959 as a distinct eating pattern among obese individuals ${ }^{(1)}$. It is defined on the basis of three main criteria: (i) excessive amount of food consumed; (ii) number of episodes of overeating and their duration; and (iii) lack of control regarding overeating $^{(2,3)}$. However, there is still no consensus about these criteria; for example, on what would be an excessive amount of food consumed.

Although recurrent episodes of binge eating defined as binging on at least two days per week are characteristic of bulimia nervosa, Spitzer et al.(4) identified a group of obese individuals with similar episodes without meeting all diagnostic criteria for bulimia nervosa. In 1994, binge eating disorder (BED) was included in Appendix B of the Diagnostic and Statistical Manual of Mental Disorders, fourth edition (DSM-IV) ${ }^{(2)}$ as a category for further investigation and is being considered for inclusion in the DSM- $\mathrm{V}^{(5)}$.

Studies with non-clinical samples have reported a wide variation in the prevalence of binge eating, which seems to be directly related to the definition used for classifying the outcome $^{(6)}$. Those evaluating recurrent binge eating have found lower prevalence rates than those who considered one or more episodes of binge eating ${ }^{(7-11)}$. Although BED is by definition regular occurrence of binge eating over a period of 6 months, studies evaluating shorter periods, e.g. 3 months, apparently show more reliable prevalence estimates $^{(12)}$. For DSM-V, standardizing the binge eating duration criterion to 3 months across diagnoses has been recommended $^{(13)}$.

Although the prevalences of bulimia nervosa and BED are low in the general population, the lifetime prevalence of symptoms of binge eating is relatively high $^{(14)}$. In Brazil, studies investigating the prevalence of binge eating and associated factors are scarce. A study carried out with a convenience sample in five Brazilian cities showed a prevalence of binge eating of $12 \cdot 9 \%{ }^{(10,11)}$. However, the subjects were selected among customers of shopping malls, which may have introduced potential biases with direct implications on the validity of the findings.

In the present study we aimed to: (i) investigate the occurrence of episodes of binge eating in both male and female adults; (ii) estimate its prevalence and describe its distribution according to demographic, socio-economic and behavioural characteristics; and (iii) assess potential 
associations with nutritional status, satisfaction with current body weight, self-rated health status and self-rated body weight. The study may contribute to the advancement of scientific knowledge by identifying groups in which binge eating is more common and exploring its association with different contemporary characteristics not only among obese individuals, but also in a representative sample of the general population.

\section{Methods}

\section{Study design and sample selection}

A cross-sectional population-based study was carried out in the city of Pelotas between January and July 2010 on a sample of non-institutionalized individuals, both male and female, aged 20-59 years, living in the urban area of the city. Pelotas is a city located in southern Brazil with 345181 inhabitants.

To estimate the prevalence of episodes of binge eating the following parameters and estimates were considered: a $95 \%$ confidence level, an estimated prevalence of binge eating episodes of $13 \%^{(10)}$ and a sample error of two percentage points (11-15\%), which resulted in a minimum sample of 1080 adults. To study the association between occurrence of binge eating episodes and independent variables, a $95 \%$ confidence level, a power of $80 \%$ and a minimum prevalence ratio of 1.6 were adopted, assuming exposure prevalence between 16\% and $72 \%$. Considering a design effect of 1.5 , including an excess of $10 \%$ for possible non-responses and $20 \%$ to control for confounders, it was estimated that a sample size of 2643 individuals would be needed.

A two-stage clustered probability sampling model was used. First, 130 of 404 primary sample units from the 2000 Geographic Operational Basis of the Brazilian Institute of Geography and Statistics ${ }^{(15)}$ were selected, with probability proportional to size according to the average income of the family head. Next, approximately ten households were systematically selected in each primary sample unit. There were 2355 eligible adults aged 20-59 years distributed in 1512 households visited.

\section{Measurements}

Binge eating behaviour was assessed using questions from the Brazilian Portuguese version of the Questionnaire on Eating and Weight Patterns (QEWP), adapted to improve its understanding for the respondents, following the definition of the American Psychiatric Association ${ }^{(2)}$ : 'In the past $<3$ months before the interview $>$, have you ever eaten so much food in a short period of time that most people would consider it an amount too big? When it happened, did you feel you could control how much or what you were eating?' Those who answered 'yes' to the first question and 'no' to the second were considered 'participants who presented episode(s) of binge eating'.
We carried out a study to test the validity of the Brazilian version adapted for the present study against the Portuguese version of the Structured Clinical Interview for DSM-IV (SCI $)^{(16)}$. A convenience sample of 214 patients who attended the clinic of the Medical School of the Federal University of Pelotas in the period between August and November 2010 was interviewed. In preliminary analyses, the tested instrument compared with the SCI showed a $\kappa$ statistic of 0.65 and yielded a sensitivity value of $60 \cdot 0 \%(95 \% \mathrm{CI} 40 \cdot 6,77 \cdot 3 \%)$ and a specificity value of $97 \cdot 8 \%(95 \%$ CI $94 \cdot 5,99 \cdot 4 \%)$.

In the present study, binge eating was defined as binging one or more times over the last 3 months before the interview and then characterized according to frequency, start time of the last episode and fasting time before the last episode. Some diagnostic criteria for BED were also evaluated: eating much more rapidly than normal, eating until feeling uncomfortably full and eating large amounts of food when not feeling physically hungry.

The following demographic variables were studied: gender (reported by the interviewer); age (in years calculated from the date of birth and categorized into age groups 20-29 years, 30-39 years, 40-49 years and 50-59 years); skin colour (defined by the interviewer and categorized into white/black/mixed); marital status (single or married/living with a partner); education (school years successfully completed, categorized into $0-4$ years, $5-8$ years and $\geqslant 9$ years); and family income (in the previous month in Brazilian currency and then divided into tertiles).

Participants were asked to rate their health status compared with other individuals of the same age as: excellent, very good, good, fair or poor. Weight was measured using a Tanita ${ }^{\circledR}$ digital scale with $150 \mathrm{~kg}$ capacity and $100 \mathrm{~g}$ precision, and height was measured using an aluminium anthropometer ( $2 \mathrm{~m}$ high; $1 \mathrm{~mm}$ precision). Measurements were taken by previously trained evaluators according to Lohman et al.'s ${ }^{(17)}$ recommendations and standardized using the Habicht method ${ }^{(18)}$. BMI $\left(\mathrm{kg} / \mathrm{m}^{2}\right)$ was calculated as weight $/$ height $^{2}$ and categorized as: underweight $(\mathrm{BMI}<$ $\left.18.5 \mathrm{~kg} / \mathrm{m}^{2}\right)$; normal weight $\left(\mathrm{BMI}=18.5-24.9 \mathrm{~kg} / \mathrm{m}^{2}\right)$; overweight $\left(\mathrm{BMI}=25 \cdot 0-29 \cdot 9 \mathrm{~kg} / \mathrm{m}^{2}\right)$; and obesity $(\mathrm{BMI} \geqslant$ $30 \cdot 0 \mathrm{~kg} / \mathrm{m}^{2}$ ).

Self-perception of body weight status was assessed both indirectly and directly, as proposed by Nunes et al. ${ }^{(19)}$, as follows.

1. Indirect assessment of body weight perception. This variable was constructed by the difference between reported ideal weight and current weight measured after the interview, resulting in a variable with three categories:

a. desire to weigh less, i.e. ideal body weight lower than current weight;

b. satisfied with current body weight, i.e. ideal weight equals (within $\pm 2 \mathrm{~kg}$ ) current weight; and 
c. desire to weigh more, i.e. ideal body weight greater than current weight.

2. Direct assessment of body weight perception or selfperceived weight status. Participants were asked whether they perceived themselves as too thin, thin, normal, fat or too fat.

During data collection, the study was widely broadcast in the local media to facilitate access of interviewers to households. All interviewers carried identification (name badge, uniform, cover letter and a copy of the published news report on the study). Before each interview, all participants were asked to read and sign a consent form.

The study questionnaires were applied by trained interviewers carefully following a protocol. They used PDA (Personal Digital Assistants) and the order of the questions was automatically determined according to a previously defined programming.

Weekly meetings with the interviewers were held to evaluate the progress of data collection. In addition, each interviewer came to the Center for Epidemiological Research twice per week to transfer data from their PDA to a database in a central computer. Data were reviewed on a weekly basis to identify inconsistencies and potential typing errors.

Anthropometric measurements were taken by the team of interviewers who visited the households after the interviews. Data were recorded on forms and all completed forms reviewed and entered in duplicate, constituting a separate database that was merged to the main database.

Soon after the interviews were complete, $10 \%$ of the participants were selected and a questionnaire for quality control was applied as close as possible to the date of the interview. The quality control form included a question on self-perceived weight status: 'How do you feel about your body weight?'

\section{Statistical analysis}

The variables were described as absolute and relative frequencies. The prevalence of binge eating according to independent variables was estimated and the association tested using the $\chi^{2}$ test for heterogeneity and linear trend and Fisher's exact test. Crude prevalence ratios and their related $95 \%$ confidence intervals of binge eating by selfrated health status, self-rated body weight, nutritional status and satisfaction with current body weight were estimated. Multivariate Poisson regression was performed to provide direct estimates of all calculated prevalence ratios, controlling for confounders (gender, age, skin colour, marital status and family income $)^{(20)}$. Statistical analyses were performed using survey (svy) commands in the Stata statistical software package version $11 \cdot 0$.

\section{Etbical aspects}

The study was approved by the Research Ethics Committee of the Federal University of Pelotas Medical School.
A written consent was obtained before each interview. All eligible individuals were contacted and informed about the study objectives, procedures, benefits and potential discomfort.

\section{Results}

The response rate in the study was $89 \%$ and a total of 2097 individuals were interviewed. Almost 20\% of all eligible individuals did not have their weight and height measured. Respondents were mostly women (56.6\%), which was significantly different from non-responders who are mostly men $(55 \cdot 0 \% ; P<0 \cdot 001)$. Both groups were similar in age $(P=0 \cdot 1)$.

Most respondents were white, reported being married or living with a partner and having $\geqslant 9$ years of schooling. About $55 \%$ never smoked, $75 \cdot 4 \%$ rated their health as excellent, very good or good, and $48.1 \%$ considered themselves 'normal' weight. Most had normal nutritional status although overweight prevalence was high (57.9\%). More than $60 \%$ of respondents reported a desire to weigh less (Table 1).

The overall prevalence of binge eating was $7 \cdot 9 \%$ (95\% CI $6 \cdot 5,9 \cdot 3 \%$ ), with a design effect of $1 \cdot 4$. For $2 \cdot 7 \%$ of respondents binge eating episodes occurred recurrently. Most respondents reported eating much more rapidly than normal, eating until feeling uncomfortably full and eating when not feeling physically hungry (Table 2 ). The episodes usually started in the morning $(32 \cdot 1 \%)$ or early evening $(26.5 \%)$, with fasting time of $<4 \mathrm{~h}$ in $40 \%$ of participants with binge eating.

Women had a significantly higher prevalence of binge eating than men $(9 \cdot 6 \% v .5 \cdot 6 \%, P=0 \cdot 001)$. The subsequent analyses are presented for the whole group taking into account that stratified analysis were also conducted showing no significant gender differences. Binge eating was more frequent among those aged 20-29 years $(11 \cdot 0 \%)$ and tended to decrease with advancing age $(P<0 \cdot 001)$. Significantly higher prevalences of binge eating were found among single individuals (9.4\%, $P=0 \cdot 04)$, those with fair or poor self-rated health status (11.5\%, $P=0 \cdot 001)$, those who perceived themselves as fat or too fat $(14 \cdot 4 \%, P<0 \cdot 001)$, the obese $(15 \cdot 6 \%, P<0 \cdot 001)$ and those who reported a desire to weigh less $(10 \cdot 4 \%$, $P<0 \cdot 001$ ). There were no significant differences by skin colour, education and tertile of family income (Table 3).

In the adjusted analysis (Table 4), self-rated health status, self-rated body weight and nutritional status remained strongly associated with binge eating, even after adjusting for potential confounders. Respondents who reported fair or poor self-rated health status had $60 \%$ higher prevalence of binge eating compared with those whose self-rated health status was excellent, very good or good.

The prevalence of binge eating was twice as high among obese individuals compared with those of normal 
Table 1 Characteristics of the sample of 2097 adults aged 20-59 years, city of Pelotas, southern Brazil, 2010

\begin{tabular}{|c|c|c|}
\hline & $n^{*}$ & $\%$ \\
\hline \multicolumn{3}{|l|}{ Gender ( $n$ 2089) } \\
\hline Male & 909 & $43 \cdot 3$ \\
\hline Female & 1188 & $56 \cdot 7$ \\
\hline \multicolumn{3}{|l|}{ Age (years) (n 2089) } \\
\hline $20-29$ & 595 & $28 \cdot 4$ \\
\hline 30-39 & 462 & $22 \cdot 0$ \\
\hline $40-49$ & 602 & $28 \cdot 7$ \\
\hline $50-59$ & 438 & $20 \cdot 9$ \\
\hline \multicolumn{3}{|l|}{ Skin colour (n 2087) } \\
\hline White & 1701 & $81 \cdot 4$ \\
\hline Black & 203 & $9 \cdot 7$ \\
\hline Mixed & 187 & $8 \cdot 9$ \\
\hline \multicolumn{3}{|l|}{ Marital status ( $n$ 2089) } \\
\hline Married/living with a partner & 1274 & $60 \cdot 7$ \\
\hline Single & 823 & $39 \cdot 3$ \\
\hline \multicolumn{3}{|l|}{ Education (years) (n 2018) } \\
\hline $0-4$ & 277 & $13 \cdot 7$ \\
\hline $5-8$ & 612 & $30 \cdot 3$ \\
\hline$\geqslant 9$ & 1133 & $56 \cdot 0$ \\
\hline \multicolumn{3}{|l|}{ Family income (tertile) } \\
\hline First (0 to $R \$ 930)$ & 570 & $27 \cdot 5$ \\
\hline Second $(R \$ 931$ to $R \$ 1815)$ & 697 & $33 \cdot 6$ \\
\hline Third ( $\mathrm{R} \$ 1816$ or more) & 806 & $38 \cdot 9$ \\
\hline \multicolumn{3}{|l|}{ Self-rated health status ( $n$ 2089) } \\
\hline Excellent/very good/good & 1581 & $75 \cdot 4$ \\
\hline Fair/poor & 515 & $24 \cdot 6$ \\
\hline \multicolumn{3}{|l|}{ Self-perceived weight status ( $n$ 2087) } \\
\hline Thin/too thin & 224 & $10 \cdot 7$ \\
\hline Normal & 1003 & $48 \cdot 1$ \\
\hline Fat/too fat & 860 & $41 \cdot 2$ \\
\hline \multicolumn{3}{|c|}{ Satisfaction with current body weight $(n 1889)$} \\
\hline Desire to weigh less & 1196 & $63 \cdot 3$ \\
\hline Satisfied with current body weight & 381 & $20 \cdot 2$ \\
\hline Desire to weigh more & 312 & $16 \cdot 5$ \\
\hline \multicolumn{3}{|l|}{ Nutritional status ( $n$ 1884)† } \\
\hline Underweight & 25 & $1 \cdot 3$ \\
\hline Normal & 768 & $40 \cdot 8$ \\
\hline Overweight & 642 & $34 \cdot 1$ \\
\hline Obesity & 449 & $23 \cdot 8$ \\
\hline
\end{tabular}

*Missing data did not exceed $3.6 \%$.

tLoss for $\mathrm{BMI}=9 \cdot 7 \%$.

nutritional status. Higher prevalence ratios were also found among those who perceived themselves as fat or too fat and those who had a desire to weigh less.

\section{Discussion}

The present population-based study conducted in southern Brazil investigated the prevalence of binge eating and associated factors in adults aged 20-59 years. The prevalence of binge eating and recurrent binge eating was $7 \cdot 9 \%$ and $2.7 \%$, respectively. In the adjusted analysis, obesity, fair/poor self-rated health status and body dissatisfaction remained strongly associated with binge eating.

A cross-sectional study of 9282 US adults aged 18 years or more ${ }^{(21)}$, using the WHO Composite International Diagnostic Interview, reported a prevalence of binge eating episodes in the last 3 months of $4.5 \%$, which is lower than we found in the city of Pelotas. A population-based
Table 2 Characteristics of binge eating among adults aged 20-59 years, city of Pelotas, southern Brazil, 2010

\begin{tabular}{|c|c|c|}
\hline & $n$ & $\%$ \\
\hline \multicolumn{3}{|l|}{ Frequency of binge eating episodes ( $n$ 160) } \\
\hline Less than twice weekly & 104 & $65 \cdot 0$ \\
\hline Twice weekly or more & 56 & $35 \cdot 0$ \\
\hline Eating much more rapidly than normal ( $n 163$ ) & 122 & $74 \cdot 8$ \\
\hline Eating until feeling uncomfortably full ( $n$ 165) & 131 & $79 \cdot 4$ \\
\hline Eating when not feeling physically hungry ( $n$ 164) & 123 & $75 \cdot 0$ \\
\hline \multicolumn{3}{|l|}{ Start time of binge eating episode ( $n$ 162) } \\
\hline 08.00 to 12.00 hours & 52 & $32 \cdot 1$ \\
\hline 12.01 to 16.00 hours & 37 & $22 \cdot 8$ \\
\hline 16.01 to 19.00 hours & 20 & $12 \cdot 4$ \\
\hline 19.01 to 22.00 hours & 43 & $26 \cdot 5$ \\
\hline After 22.00 hours & 10 & $6 \cdot 2$ \\
\hline \multicolumn{3}{|l|}{ Fasting time before binge eating (h) ( $n$ 165) } \\
\hline$<4$ & 66 & $40 \cdot 0$ \\
\hline $4-7$ & 55 & $33 \cdot 3$ \\
\hline$\geqslant 8$ & 44 & $26 \cdot 7$ \\
\hline
\end{tabular}

study conducted in Australia $^{(22)}$ with individuals aged 15-94 years, using questions from the Eating Disorder Examination, showed that about $3 \%$ of respondents had regular episodes of binge eating at least twice weekly in the last 3 months. This prevalence is similar to that found in the present study $(2 \cdot 7 \%)$.

Evidently, most individuals with binge eating shared common characteristics with BED cases, like eating much more rapidly than normal, eating until feeling uncomfortably full and eating when not feeling physically hungry. Since ours was a study screening for binge eating, it was not possible to identify cases of BED and bulimia nervosa, considering that would be necessary to investigate other related factors.

The findings of the present study showed that binge eating episodes occurred most frequently in the early morning and early evening. While studying patients with non-purging binge eating, Allison and Timmerman ${ }^{(23)}$ found that these episodes occurred most frequently during dinner and lunch. Raymond et $a l^{(24)}$ showed that greater energy intake occurred in the early evening, followed by lunchtime.

To our knowledge there are no other studies on the duration of fasting preceding episodes of binge eating. Our initial hypothesis that these episodes would occur more frequently when the duration of fasting was greater was not confirmed. Forty per cent of respondents who met criteria for binge eating reported that the last episode occurred after a fasting time of $<4 \mathrm{~h}$.

Studies have shown that binge eating is more common among younger white women ${ }^{(8,25)}$. The present study showed that women had a significantly higher prevalence of binge eating than men. Although it may seem a consensus in the literature, there are few population-based studies that have included both genders in the sample.

A multicentre study in Brazil $^{(10,11)}$ found a binge eating prevalence of $13 \cdot 0 \%$ for women and $12 \cdot 8 \%$ among men, with no statistically significant gender difference. 
Table 3 Prevalence of binge eating according to independent variables among adults aged 20-59 years, city of Pelotas, southern Brazil, 2010

\begin{tabular}{|c|c|c|c|c|}
\hline & $n$ & $\% *$ & $95 \% \mathrm{Cl}$ & $P$ valuet \\
\hline \multicolumn{5}{|l|}{ Gender ( $n$ 2089) } \\
\hline Male & 906 & $5 \cdot 6$ & $4 \cdot 0,7 \cdot 2$ & \multirow[t]{2}{*}{$0 \cdot 001$} \\
\hline Female & 1183 & $9 \cdot 6$ & $7 \cdot 7,11 \cdot 5$ & \\
\hline \multicolumn{5}{|l|}{ Age (years) (n 2089) } \\
\hline $20-29$ & 593 & $11 \cdot 0$ & $7 \cdot 9,14 \cdot 0$ & \multirow[t]{4}{*}{$<0.001$} \\
\hline 30-39 & 461 & $9 \cdot 5$ & $6 \cdot 6,12 \cdot 4$ & \\
\hline $40-49$ & 600 & $6 \cdot 0$ & $4 \cdot 0,8 \cdot 0$ & \\
\hline $50-59$ & 435 & $4 \cdot 6$ & $2 \cdot 8,6 \cdot 4$ & \\
\hline \multicolumn{5}{|l|}{ Skin colour ( $n$ 2087) } \\
\hline White & 1693 & $7 \cdot 4$ & $6 \cdot 1,8 \cdot 8$ & \multirow[t]{3}{*}{$0 \cdot 2$} \\
\hline Black & 203 & $8 \cdot 9$ & $5 \cdot 1,12 \cdot 6$ & \\
\hline Mixed & 187 & $10 \cdot 7$ & $5 \cdot 9,15 \cdot 5$ & \\
\hline \multicolumn{5}{|l|}{ Marital status (n 2089) } \\
\hline Married/living with a partner & 1272 & $6 \cdot 9$ & $5 \cdot 4,8 \cdot 4$ & \multirow[t]{2}{*}{0.04} \\
\hline Single & 817 & $9 \cdot 4$ & $7 \cdot 2,11 \cdot 6$ & \\
\hline \multicolumn{5}{|l|}{ Education (years) (n 2018) } \\
\hline $0-4$ & 277 & $5 \cdot 4$ & $2 \cdot 9,7 \cdot 9$ & \multirow[t]{3}{*}{$0 \cdot 3$} \\
\hline $5-8$ & 610 & $8 \cdot 2$ & $6 \cdot 0,10 \cdot 4$ & \\
\hline$\geqslant 9$ & 1131 & $8 \cdot 3$ & $6 \cdot 4,10 \cdot 2$ & \\
\hline \multicolumn{5}{|l|}{ Family income (tertile) (n 2065) } \\
\hline First & 568 & $8 \cdot 1$ & $5 \cdot 7,10 \cdot 5$ & \multirow[t]{3}{*}{$0 \cdot 9$} \\
\hline Second & 694 & $7 \cdot 9$ & $5 \cdot 5,10 \cdot 4$ & \\
\hline Third & 803 & $7 \cdot 9$ & $5 \cdot 7,10 \cdot 0$ & \\
\hline \multicolumn{5}{|l|}{ Self-rated health status ( $n$ 2089) } \\
\hline Excellent/very good/good & 1578 & $6 \cdot 7$ & $5 \cdot 2,8 \cdot 2$ & \multirow[t]{2}{*}{$0 \cdot 001$} \\
\hline Fair/poor & 511 & $11 \cdot 5$ & $8 \cdot 6,14 \cdot 5$ & \\
\hline \multicolumn{5}{|l|}{ Self-rated body weight ( $n$ 1181) } \\
\hline Thin/too thin & 223 & $2 \cdot 7$ & $0 \cdot 7,4 \cdot 7$ & \multirow[t]{3}{*}{$<0.001$} \\
\hline Normal & 1002 & $3 \cdot 5$ & $2 \cdot 2,4 \cdot 7$ & \\
\hline Fat/too fat & 860 & $14 \cdot 4$ & $11 \cdot 8,17 \cdot 0$ & \\
\hline \multicolumn{5}{|l|}{ Nutritional status ( $n$ 1891) } \\
\hline Normal & 768 & $3 \cdot 8$ & $2 \cdot 3,5 \cdot 2$ & \multirow[t]{3}{*}{$<0.001$} \\
\hline Overweight & 640 & $6 \cdot 6$ & $4 \cdot 7,8 \cdot 4$ & \\
\hline Obesity & 448 & $15 \cdot 6$ & $12 \cdot 1,19 \cdot 1$ & \\
\hline \multicolumn{5}{|c|}{ Satisfaction with current body weight ( $n$ 1888) } \\
\hline Desire to weigh less & 1196 & $10 \cdot 4$ & $8 \cdot 4,12 \cdot 3$ & \multirow[t]{3}{*}{$<0.001$} \\
\hline Satisfied with current body weight & 380 & $1 \cdot 8$ & $0 \cdot 5,3 \cdot 1$ & \\
\hline Desire to weigh more & 312 & $3 \cdot 2$ & $1 \cdot 4,5 \cdot 0$ & \\
\hline
\end{tabular}

*Participants who binged one or more times over the last 3 months. tFisher's exact test.

Studies on women only were identified. Freitas et $a l^{(8)}$ carried out a study in Rio de Janeiro, Brazil, where they evaluated 1295 women aged 35 years or more and found a $20.6 \%$ prevalence of binge eating in the 6 months preceding the interview.

In Pelotas we found that binge eating was more frequent among younger individuals and its prevalence tended to decrease with advancing age. However, individuals aged 40 years or more had a considerable high prevalence of binge eating.

Self-rated health status has been identified as an indicator that summarizes various components that comprise our understanding of health. A strong negative association between this indicator and binge eating episodes was found among women in Rio de Janeiro, Brazil ${ }^{(8)}$. A higher prevalence of binge eating among those who reported poor self-rated health status was also seen in our study in Pelotas.

Several researchers have shown a relationship between binge eating and excess weight ${ }^{(8-11)}$. Hasler et al. ${ }^{(26)}$ studied a population-based prospective cohort with
591 young adults followed up for 19 to 40 years and showed that binge eating episodes were associated with increased weight gain and clinically significant weight-related problems. Our results in Pelotas reinforced that binge eating was significantly more frequent among obese individuals, regardless of potential confounders such as self-rated body weight or satisfaction with current body weight.

Although binge eating and self-perception of body weight appear to be related, this association has not been clearly described in previous studies. A study with a clinical sample of women ${ }^{(27)}$ found no differences between binge eaters and non-binge eaters regarding their estimation of ideal or current body size based on the silhouette selection method. In contrast, $\mathrm{Cash}^{(28)}$ evaluated obese women who were binge eaters and found they reported greater body dissatisfaction and more negatively assessed their appearance than those not binge eating. In the present study, the association between binge eating and self-rated body weight remained significant even after adjustment. Those who perceived 
Table 4 Crude and adjusted prevalence ratios (PR) of binge eating episodes according to independent variables among adults aged 20-59 years, city of Pelotas, southern Brazil, 2010

\begin{tabular}{|c|c|c|c|}
\hline & $\begin{array}{l}\text { Crude } \\
\text { PR }\end{array}$ & $\begin{array}{l}\text { Adjusted } \\
\text { PR }^{*}\end{array}$ & $95 \% \mathrm{Cl}$ \\
\hline \multicolumn{4}{|l|}{ Self-rated health status } \\
\hline Excellent/very good/good & $1 \cdot 0$ & $1 \cdot 0$ & - \\
\hline $\begin{array}{l}\text { Fair/poor } \\
P \text { value }\end{array}$ & $1 \cdot 7$ & $1 \cdot 6$ & $\begin{array}{r}1 \cdot 1,2 \cdot 3 \\
0 \cdot 007\end{array}$ \\
\hline \multicolumn{4}{|l|}{ Nutritional status } \\
\hline Normal & $1 \cdot 0$ & $1 \cdot 0$ & - \\
\hline Overweight & $1 \cdot 7$ & $1 \cdot 4$ & $0 \cdot 8,2 \cdot 4$ \\
\hline Obesity & $4 \cdot 1$ & $2 \cdot 2$ & $1 \cdot 2,3 \cdot 7$ \\
\hline$P$ value & & & $<0.001$ \\
\hline \multicolumn{4}{|l|}{ Self-rated body weight } \\
\hline Thin/too thin & $0 \cdot 8$ & $1 \cdot 0$ & $0 \cdot 4,2 \cdot 3$ \\
\hline Normal & $1 \cdot 0$ & $1 \cdot 0$ & - \\
\hline $\mathrm{Fat} /$ too fat & $4 \cdot 1$ & $2 \cdot 1$ & $\begin{array}{r}1 \cdot 3,3 \cdot 4 \\
0.008\end{array}$ \\
\hline \multicolumn{4}{|l|}{ Satisfaction with current body weight } \\
\hline Desire to weigh less & $5 \cdot 6$ & $2 \cdot 4$ & $1 \cdot 1,5 \cdot 3$ \\
\hline Satisfied with current body weight & $1 \cdot 0$ & $1 \cdot 0$ & - \\
\hline $\begin{array}{l}\text { Desire to weigh more } \\
P \text { value }\end{array}$ & $1 \cdot 7$ & 1.9 & $\begin{array}{c}0 \cdot 7,5 \cdot 1 \\
0 \cdot 08\end{array}$ \\
\hline
\end{tabular}

*Model included the four main independent variables (self-rated health status, nutritional status, self-rated body weight and satisfaction with current body weight), additionally adjusting for potential confounders (gender, age, skin colour, marital status and family income).

themselves as fat or very fat had a significantly higher prevalence of binge eating.

The perception of excess body weight has been used as a way of expressing body dissatisfaction, which could lead to an eating disorder through the use of restrictive diets or by triggering negative emotions related to low self-esteem $^{(29)}$. In the present study, we included an indirect measure of satisfaction with current body weight, the difference between reported ideal weight and measured weight. Those who desired to weigh less had a threefold higher prevalence of binge eating compared with those who were 'satisfied' with their weight. Hence, it seems that the desire to weigh less, or being dissatisfied with one's own body, is a predictor of binge eating as important as self-rated body weight.

Methodological procedures and quality control of data applied in the present study included training of interviewers, standardized anthropometric measures and direct supervision of field work. All these aspects contributed to the internal validity and constitute strengths of our study.

The main limitation of our study is the fact that no standardized questions have been developed aiming to screen binge eating episodes in population-based studies, which hampers comparison of the results with existing literature. Nevertheless, preliminary results of the validation study of the version of QEWP-R adapted for the present study indicated that it can be a useful first-step screening procedure to identify individuals with episodes of binge eating.

The cross-sectional design applied in our study allowed to us show robust associations between binge eating and independent variables. However the results should be interpreted with caution, considering the possibility of reverse or bidirectional causality. Eating behaviour, obesity, self-rated health status and satisfaction with current body weight share risk factors and are interrelated $^{(30)}$. Aetiological research investigating the paths connecting these outcomes is scarce. Therefore the findings of the present study highlight the need for further longitudinal studies which can better address the issue of bidirectional or reverse causality.

\section{Conclusion}

The present results showed a high prevalence of binge eating among adults in Pelotas, being higher among younger women. Nutritional status, self-rated health status and body weight self-perception remained associated with binge eating even after adjusting for potential confounders. We emphasize the need for further studies of binge eating among men to identify whether these associations have the same direction and magnitude as in women.

\section{Acknowledgements}

Sources of funding: G.V.A.F. was supported by a grant from the Coordenação de Aperfeiçoamento de Pessoal de Nível Superior (CAPES) and M.T.A.O. was supported by National Council of Technological and Scientific Development (CNPq PQ n 304793/2012-8). Conflict of interest declaration: No conflicts of interest exist. Authors' contributions: G.V.A.F was responsible for data collection, analysis and drafted the results of the study. M.T.A.O. supervised the study, contributed to the analyses and writing. D.P.G. supervised the study, participated in the analyses and writing. All of the authors read and approved the final manuscript. Acknowledgements: The authors would like to thank the researchers at the Center for Epidemiologic Research at the Federal University of Pelotas for their assistance.

\section{References}

1. Stunkard AJ (1959) Eating patterns and obesity. Psychiatr $Q$ 33, 284-295.

2. American Psychiatric Association (1994) Diagnostic and Statistical Manual of Mental Disorders, 4th ed. Washington, DC: APA.

3. Spitzer RL, Yanovski S, Wadden T et al. (1993) Binge eating disorder: its further validation in a multisite study. Int J Eat Disord 13, 137-153.

4 Spitzer RL, Devlin M, Walsh BT et al. (1992) Binge eating disorder: a multisite field trial of the diagnostic criteria. Int J Eat Disord 11, 191-203.

5. Wonderlich SA, Gordon KH, Mitchell JE et al. (2009) The validity and clinical utility of binge eating disorder. Int $J$ Eat Disord 42, 687-705.

6. Wolfe BE, Baker CW, Smith AT et al. (2009) Validity and utility of the current definition of binge eating. Int $J$ Eat Disord 42, 674-686. 
7. Borges MBF, Jorge MR, Morgan CM et al. (2002) Binge-eating disorder in Brazilian women on a weight-loss program. Obes Res 10, 1127-1134.

8. Freitas SR, Appolinario JC, Souza MA et al. (2008) Prevalence of binge eating and associated factors in a Brazilian probability sample of midlife women. Int J Eat Disord 41, 471-478.

9. French SA, Jeffery RW, Sherwood NE et al. (1999) Prevalence and correlates of binge eating in a nonclinical sample of women enrolled in a weight gain prevention program. Int J Obes Relat Metab Disord 23, 576-585.

10. Siqueira KS, Appolinario JC \& Sichieri R (2004) Overweight, obesity, and binge eating in a non-clinical sample of five Brazilian cities. Obes Res 12, 1921-1924.

11. Siqueira KS, Appolinario JC \& Sichieri R (2005) Relationship between binge-eating episodes and self-perception of body weight in a nonclinical sample of five Brazilian cities. Rev Bras Psiquiatr 27, 290-294.

12. Wilson GT \& Sysko R (2009) Frequency of binge eating episodes in bulimia nervosa and binge eating disorder: diagnostic considerations. Int J Eat Disord 42, 603-610.

13. Wilfley DE, Bishop ME, Wilson GT et al. (2007) Classification of eating disorders: toward DSM-V. Int J Eat Disord $\mathbf{4 0}$, Suppl., S123-S129.

14. Trace SE, Thornton LM, Root TL et al. (2012) Effects of reducing the frequency and duration criteria for binge eating on lifetime prevalence of bulimia nervosa and binge eating disorder: implications for DSM-5. Int J Eat Disord 45, 531-536.

15. Instituto Brasileiro de Geografia e Estatística (2004) Resultados da Amostra do Censo Demográfico 2000 Malha municipal digital do Brasil: situação em 2001. Rio de Janeiro: IBGE.

16. Del-Ben CM, Avilela JA, de S Crippa JA et al. (2001) Reliability of the structured clinical interview for DSM-IV clinical version translated into Portuguese. Rev Bras Psiquiatr 23, 156-159.

17. Lohman TG, Roche AF \& Martorell R (1988) Anthropometric Standardization Reference Manual. Champaign, IL: Human Kinetics.

18. Habicht JP (1974) Estandarizacion de metodos epidemiologicos cuantitativos sobre el terreno. Bol Oficina Sanit Panam 76, 375-384.
19. Nunes MA, Olinto MTA, Barros FC et al. (2001) Influência da percepção do peso e do índice de massa corporal nos comportamentos alimentares anormais. Rev Bras Psiquiatr 23, 21-27.

20. Barros AJ \& Hirakata VN (2003) Alternatives for logistic regression in cross-sectional studies: an empirical comparison of models that directly estimate the prevalence ratio. BMC Med Res Methodol 3, 21.

21. Hudson JI, Hiripi E, Pope HGJ et al. (2007) The prevalence and correlates of eating disorders in the National Comorbidity Survey Replication. Biol Psychiatry 61, 348-358.

22. Hay P (1998) The epidemiology of eating disorder behaviors: an Australian Community-Based Survey. Int $J$ Eat Disord 23, 371-382.

23. Allison S \& Timmerman GM (2007) Anatomy of a binge: food environment and characteristics of nonpurge binge episodes. Eat Behav 8, 31-38.

24. Raymond RC, Bartholome LT, Lee SS et al. (2007) A comparison of energy intake and food selection during laboratory binge eating episodes in obese women with and without a binge eating disorder diagnosis. Int J Eat Disord 40, 67-71.

25. Striegel-Moore RH (2000) The epidemiology of binge eating. Eur Eat Disord Rev 8, 344-346.

26. Hasler G, Pine DS, Gamma A et al. (2004) The associations between psychopathology and being overweight: a 20-year prospective study. Psychol Med 34, 1047-1057.

27. Davis CJ, Williamson DA, Goreczny AJ et al. (1989) Bodyimage disturbances and bulimia nervosa: an empirical analysis of recent revisions of the DSM-III. Behav Assess $\mathbf{1 1}$ 61-69.

28. Cash TF (1991) Binge eating and body images among the obese: a further evaluation. J Soc Behav Pers 6, 367-376.

29. Stice E (1999) Clinical implications of psychosocial research on bulimia nervosa and binge-eating disorder. J Clin Psychol 55, 675-683.

30. Haines J \& Neumark-Sztainer D (2006) Prevention of obesity and eating disorders: a consideration of shared risk factors. Health Educ Res 21, 770-782. 